Check for updates

Cite this: RSC Adv., 2021, 11, 12374

\section{Synthesis of some new distyrylbenzene derivatives using immobilized Pd on an NHC-functionalized MIL-101(Cr) catalyst: photophysical property evaluation, DFT and TD-DFT calculations $\uparrow$}

\begin{abstract}
Esmaeil Niknam, ${ }^{a}$ Ali Mahmoodi, ${ }^{b}$ Farhad Panahi, (D) *a Maryam Heydari Dokoohaki, ${ }^{a}$ Amin Reza Zolghadr ${ }^{a}$ and Ali Khalafi-Nezhad ${ }^{\star a}$

In this study the catalytic application of a heterogeneous $\mathrm{Pd}$-catalyst system based on metal organic framework [Pd-NHC-MIL-101(Cr)] was investigated in the synthesis of distyrylbenzene derivatives using the Heck reaction. The Pd-NHC-MIL-101(Cr) catalyst showed high efficiency in the synthesis of these $\pi$-conjugated materials and products were obtained in high yields with low Pd-contamination based on ICP analysis. The photophysical behaviors for some of the synthesized distyrylbenzene derivatives were evaluated. The DFT and TD-DFT methods were employed to determine the optimized molecular geometry, band gap energy, and the electronic absorption and emission wavelengths of the new synthesized donor- $\pi$-acceptor $(D-\pi-A)$ molecules in the gas phase and in various solvents using the chemical model B3LYP/6-31+G(d,p) level of theory.
\end{abstract}

Received 19th January 2021

Accepted 22nd March 2021

DOI: $10.1039 / \mathrm{d} 1 \mathrm{ra00457c}$

rsc.li/rsc-advances

\section{Introduction}

The synthesis of fluorescent compounds to be used in organic light emitting diodes (OLEDs),,$^{1-5}$ solar cells, ${ }^{6,7}$ organic field effect transistors (OFETs), ${ }^{8,9}$ sensing, ${ }^{10-12}$ and fluorescent probes $^{13-16}$ is highly considered. Stilbene compounds are a significant class of fluorescent organic $\pi$-conjugated compounds, which are widely used in the above mentioned applications. ${ }^{17-26}$ Due to the systematic relationship between the fluorescence properties of the fluorescent materials and their chemical structures, stilbenes are an interesting class of compounds which permit us to simply fine tune the photophysical properties via available chemical modifications. ${ }^{27-31}$ To synthesize stilbenes, different organic methodologies such as Wittig reaction, ${ }^{32-34}$ Horner-Wadsworth-Emmons reaction, ${ }^{35}$ catalytic aldehyde olefinations, ${ }^{36}$ and Mizoroki-Heck reaction $^{37,38}$ have been developed. Palladium-catalyzed coupling reactions are key tools in stilbene synthesis because they consist of a family of cross coupling reactions, allowing diversity oriented synthesize of stilbenes. ${ }^{39-42}$ Thus, Mizoroki-Heck reaction has been extensively used in the synthesis of stilbene compounds. ${ }^{43,44}$

\footnotetext{
${ }^{a}$ Department of Chemistry, College of Sciences, Shiraz University, Shiraz 71454, Iran. E-mail:panahi@shirazu.ac.ir; panahichem@ymail.com

${ }^{b}$ Department of Polymer Engineering and Color Technology, Amirkabir University of Technology, Tehran, Iran

$\dagger$ Electronic supplementary information (ESI) available: Spectral data, copy of ${ }^{1} \mathrm{H}$ NMR and ${ }^{13} \mathrm{C}$ NMR of synthesized compounds, and some photophysical data of fluorescence compounds. See DOI: 10.1039/d1ra00457c
}

In this work, in continuation of our program on the synthesis of stilbene derivatives, ${ }^{45-50}$ a highly efficient heterogeneous catalyst system [Pd-NHC-MIL-101(Cr) $]^{51}$ was introduced to be applied in the synthesis of stilbene derivatives using MizorokiHeck coupling reaction. ${ }^{52-57}$ The Pd-NHC-MIL-101(Cr) catalyst system showed remarkable catalytic activity in the Heck reaction $^{51}$ and in order to further show its utility in organic synthesis we investigate its applicability in the synthesis of distyrylbenzenes (DSBs). The synthetic pathway toward synthesis of [Pd-NHC-MIL-101(Cr)] catalyst system is shown in Scheme 1.

\section{Results and discussion}

Catalytic activity evaluation of Pd-NHC-MIL-101(Cr) catalyst in the synthesis of distyrylbenzenes (DSBs)

In order to show the catalytic applicability of [Pd-NHC-MIL$101(\mathrm{Cr})]$ catalyst in the synthesis of DSBs and stilbenes, a model reaction was selected and different conditions were checked to obtain high yields of desired products (Table 1).

As shown in Table 1, using different ratios of starting materials in the presence of Pd-NHC-MIL-101(Cr) catalyst, it is possible to obtain both compounds $\mathbf{3} \mathbf{a}$ and $\mathbf{3} \mathbf{a}^{\prime}$ in high yields. In order to synthesize DSBs in high yield, the ratio of aryl halide to 1,4-distylbenzene was selected 2.2 to 1 (Table 1, entry 4). Also, the best yield for mono-substituted product was achieved using $1: 2.2$ ratios for $\mathbf{1 a}: \mathbf{2 a}$ (Table 1, entry 3). No improvement in the reaction yield was observed by increasing the catalyst loading more than $1.5 \mathrm{~mol} \%$ (Table 1, entries $5-8$ ). ${ }^{58}$ Using Pd/C as a traditional catalyst, ${ }^{59-62} 3 \mathbf{a}^{\prime}$ was obtained in lower yield of 


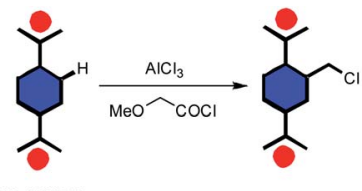

MIL-101(Cr)

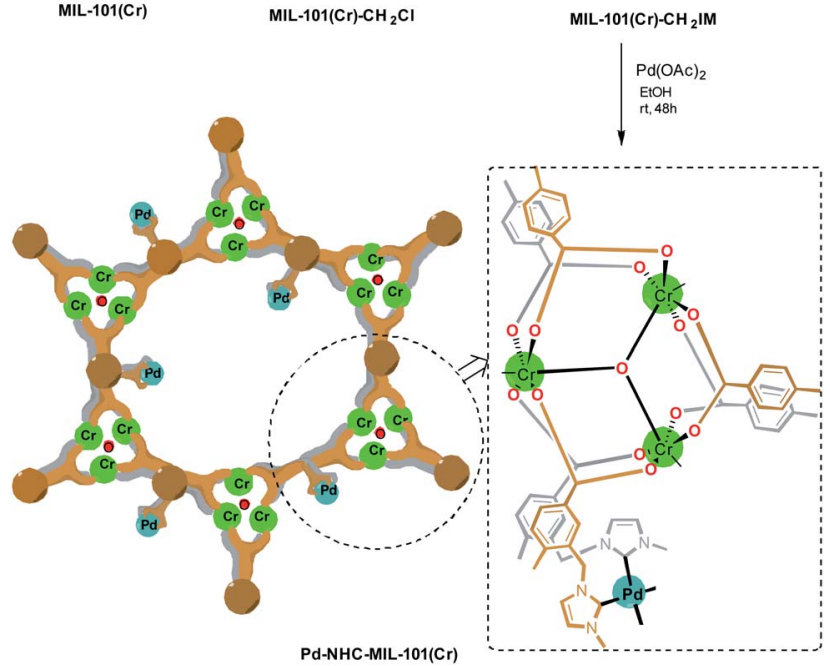

Scheme 1 Synthetic rote to synthesize [Pd-NHC-MIL-101(Cr)] catalyst.

Table 1 Optimization of the Pd-NHC-MIL-101(Cr)-catalyzed Heck reaction between aryl halides and 1,4-distylbenzene ${ }^{a}$

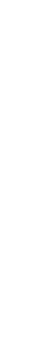

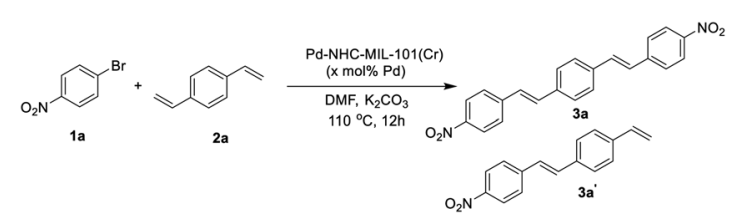

\begin{tabular}{lllll}
\hline Entry & $x$ & $\mathbf{1 a}: \mathbf{2 a}$ ratio & ${\text { Yield } 3 \mathbf{a}^{b}}^{b}$ & ${\text { Yield } 3 \mathbf{a}^{\prime}}^{b}$ \\
\hline 1 & 1.5 & $1: 2$ & 6 & $85(79)$ \\
2 & 1.5 & $2: 1$ & 70 & 20 \\
3 & 1.5 & $1: 2.2$ & 5 & $88(81)$ \\
4 & 1.5 & $2.2: 1$ & $83(77)$ & 2 \\
5 & 1.25 & $1: 2.2$ & 6 & $78(71)$ \\
6 & 1.25 & $2.2: 1$ & 70 & 8 \\
7 & 2.0 & $1: 2.2$ & 4 & $87(78)$ \\
8 & 2.0 & $2.2: 1$ & 84 & 20 \\
9 & 1.5 & $1: 2.2$ & 20 & $58^{c}$ \\
10 & 1.5 & $2.2: 1$ & 71 & $18^{c}$
\end{tabular}

${ }^{a}$ Reaction conditions: 1a $(1.0 \mathrm{mmol}), \mathbf{2 a}$ (based on the ratio), Pd-NHCMIL-101(Cr) $(x \mathrm{~mol} \%)$, DMF (5 mL), $\mathrm{K}_{2} \mathrm{CO}_{3}(2.5 \mathrm{mmol}), 110{ }^{\circ} \mathrm{C}, 12 \mathrm{~h}$. ${ }^{b}$ NMR yield. ${ }^{c}$ The $\mathrm{Pd} / \mathrm{C}$ was used as catalyst. The yields in parentheses related to isolated yields.

$58 \%$ (same conditions and stoichiometry), demonstrating important role of MOF structure in homoselectivity ${ }^{63}$ to obtain $3 \mathbf{a}^{\prime}$ in high yield (Table 1, entries $9 \& 10$ ). Also, the ICP analysis of the product using Pd-NHC-MIL-101(Cr) catalyst showed less than $2 \mathrm{ppm}$ of $\mathrm{Pd}$ while the amount of Pd-content for the product obtained using $\mathrm{Pd} / \mathrm{C}$ catalyst was around $16 \mathrm{ppm}$. This experiment showed that the efficacy of this Pd MOF-based catalyst in the synthesis of this class of $\pi$-conjugated materials with low Pd-contamination which is very important in their applications.

Next we checked the synthesis of DSB derivatives using the reaction of 1,4-dibromobenzene and styrene (Table 2). The PdNHC-MIL-101(Cr) catalyst can effectively catalyze this coupling reaction and it is possible to control the reaction to obtain both 3a and $\mathbf{3} \mathbf{a}^{\prime \prime}$ in high yields. The synthesis of $\mathbf{3} \mathbf{a}^{\prime \prime}$ is important because it can be used for the synthesis of unsymmetrical DSB incorporating two different functional groups in the ends of piconjugated system. ${ }^{50}$ Using 1.5 mol\% of Pd-NHC-MIL-101(Cr) catalyst and ratio of $1: 2.2$ for $\mathbf{4 a}: 5 \mathbf{a}$, DSB 3a was obtained in $84 \%$ isolated yield (Table 2, entry 3). Employing the same catalyst loading and reveres ratio of $4 \mathbf{a}: 5 \mathbf{a}(2.2: 1)$, compound $3 \mathbf{a}^{\prime \prime}$ was obtained in $86 \%$ (Table 2 , entry 4). Again, in order to check the homoselectivity of the Pd-NHC-MIL-101(Cr) catalyst in mono-functionalization using Heck chemistry the reaction was checked using a $\mathrm{Pd} / \mathrm{C}$ catalyst. Using this catalyst system compound $3 \mathbf{a}^{\prime \prime}$ was obtained in lower yield of $63 \%$ (same conditions and stoichiometry). This experiment also represents the key role of MOF structure in homoselectivity (Table 2, entries 5 \& 6). The Pd content of the products in this reaction was also evaluated using ICP analysis and it was observed that the obtained product using Pd-NHC-MIL-101(Cr) catalyst has only $3.1 \mathrm{ppm}$ of $\mathrm{Pd}$, while for the product obtained in the presence of homogeneous is around $22 \mathrm{ppm}$. Accordingly, this heterogeneous Pd catalyst system based on MOF is efficient in the synthesis of DSBs with low Pd-contamination.

After optimization of the reaction conditions, in order to show the applicability of this catalyst system in synthesis of stilbene and DSBs, some different derivatives were synthesized and results are depicted in Fig. 1.

As shown in Fig. 1, both electron-withdrawing and electrondonating groups on aryl rings worked well with this methodology. The synthesis of these DSBs is important. For example,

Table 2 Optimization of the Pd-NHC-MIL-101(Cr)-catalyzed Heck reaction between 1,4-dibromobenzene and stylbenzene ${ }^{a}$

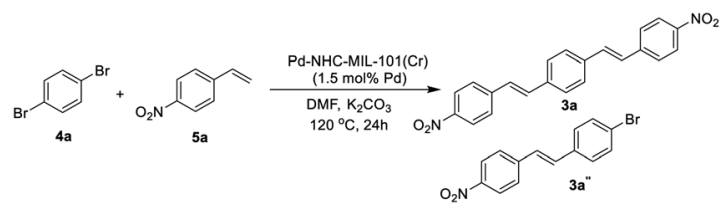

\begin{tabular}{llll}
\hline Entry & $\mathbf{4 a}: \mathbf{5 a}$ ratio & ${\text { Yield } \mathbf{3} \mathbf{a}^{b}}$ & ${\text { Yield } \mathbf{3} \mathbf{a}^{\prime \prime}}^{b}$ \\
\hline 1 & $1: 2$ & $82(76)$ & 12 \\
2 & $2: 1$ & 4 & $80(73)$ \\
3 & $1: 2.2$ & $84(77)$ & 8 \\
4 & $2.2: 1$ & 2 & $86(79)$ \\
5 & $1: 2.2$ & 69 & $19^{c}$ \\
6 & $2.2: 1$ & 21 & $63^{c}$
\end{tabular}

${ }^{a}$ Reaction conditions: 1a $(1.0 \mathrm{mmol}), \mathbf{2 a}$ (based on the ratio), Pd-NHCMIL-101(Cr) (1.5 mol\%), DMF (5 mL), $\mathrm{K}_{2} \mathrm{CO}_{3}(2.5 \mathrm{mmol}), 110^{\circ} \mathrm{C}, 12 \mathrm{~h}$. ${ }^{b}$ NMR yield. ${ }^{c}$ The $\mathrm{Pd} / \mathrm{C}$ was used as catalyst. The yields in parentheses related to isolated yields. 

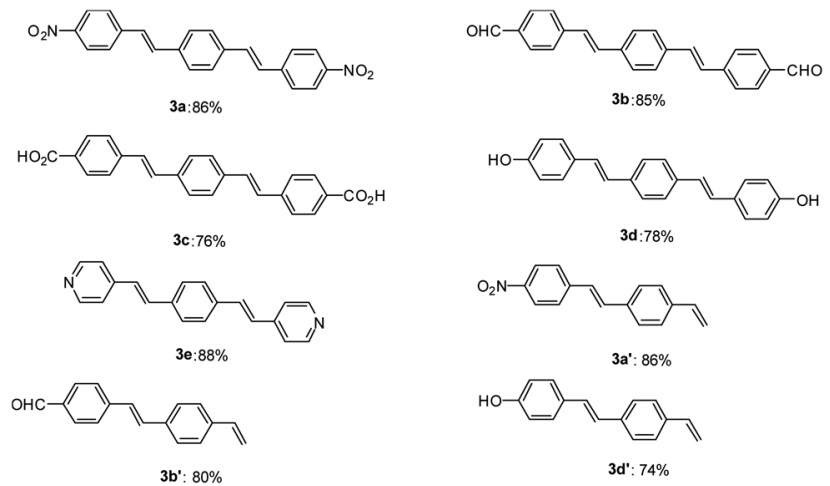

Fig. 1 Synthesis of diverse symmetrical DSBs and vinyl-functionalized stilbenes using Pd-NHC-MIL-101(Cr) catalyst. Reaction conditions for compound (3a-e): 1,4-divinylbenzene $(0.55 \mathrm{mmol})$, aryl halide (1.0 $\mathrm{mmol})$, base $(2.0 \mathrm{mmol})$, amount of catalyst $12.0 \mathrm{mg}(1.5 \mathrm{~mol} \%)$, solvent $(5 \mathrm{~mL}), 12 \mathrm{~h}$ at $110^{\circ} \mathrm{C}$. Reaction conditions for compound $\left(3 \mathrm{a}^{\prime}, 3 \mathrm{~b}^{\prime}\right.$ and $\left.3 \mathrm{~d}^{\prime}\right)$ : 1,4-divinylbenzene $(1.1 \mathrm{mmol})$, aryl halide $(1.0 \mathrm{mmol})$, base $(2.0$ $\mathrm{mmol})$, amount of catalyst $12.0 \mathrm{mg}(1.5 \mathrm{~mol} \%)$, solvent $(5 \mathrm{~mL}), 12 \mathrm{~h}$ at $110^{\circ} \mathrm{C}$. All yields correspond to the isolated product.

compound $\mathbf{3 b}$ derivatives were used as an amine-sensitive dye for detection of proteins. ${ }^{64}$ These stilbene derivatives were also used for the preparation of polycyclic aromatic hydrocarbons (PAHs) and nanographene. ${ }^{65}$ Synthesis of hydroxylated stilbenes is important in biological application point of view and using this catalyst system, compounds $\mathbf{3 d}$ and $\mathbf{3} \mathbf{d}^{\prime}$ was successfully synthesized in high yields. ${ }^{6}$ Pyridine-based stilbenes are important in the preparation of porous coordination polymers. ${ }^{67}$

The catalytic applicability of Pd-NHC-MIL-101(Cr) catalyst system was also investigated in the synthesis of unsymmetrical DSBs under optimized conditions. First, some aminefunctionalized aryl bromides were synthesized using a $\mathrm{Cu}-$ catalyzed $\mathrm{N}$-arylation reaction based on a known procedure in the literature (Scheme 2). ${ }^{68}$

The Mizoroki-Heck coupling reaction between synthetic amine-functionalized aryl halides (7a-e) and compound $\mathbf{3} \mathbf{b}^{\prime}$ in the presence of Pd-NHC-MIL-101(Cr) catalyst afforded D- $\pi-\mathrm{A}$ systems in high isolated yields (Fig. 2).

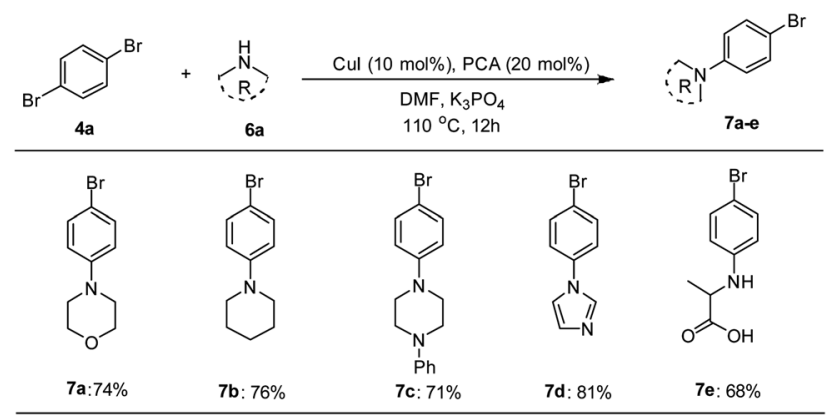

Scheme 2 Synthesis of amine-functionalized aryl bromides using Cucatalyzed $\mathrm{N}$-arylation reaction. ${ }^{a, b}{ }^{a}$ Reaction conditions: 1,4-dibromobenzene $(1.0 \mathrm{mmol})$, amine $(1.0 \mathrm{mmol})$, base $(2.0 \mathrm{mmol}), \mathrm{Cul}$ catalyst (10.0 mol\%), picolinic acid (PCA, $20 \mathrm{~mol} \%), \mathrm{DMF}(5 \mathrm{~mL}), 12 \mathrm{~h}$ at $110{ }^{\circ} \mathrm{C}$. ${ }^{b}$ Isolated yield.

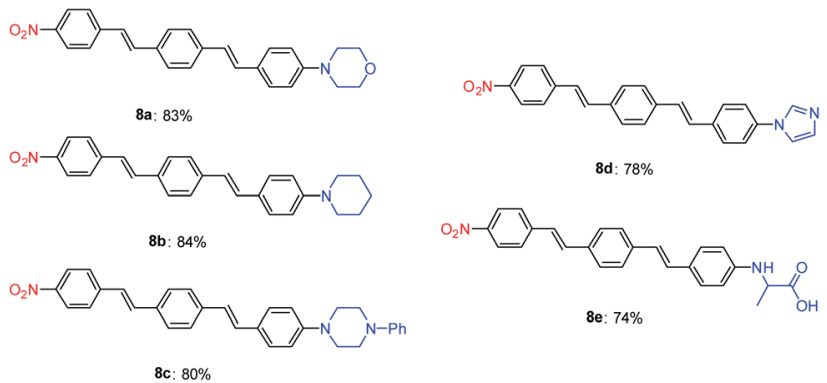

Fig. 2 Synthesis of diverse D- $\pi-A$ DSBs using Pd-NHC-MIL-101(Cr) catalyst. ${ }^{a, b}{ }^{a}$ Reaction conditions: $3 a^{\prime}(1.0 \mathrm{mmol})$, aryl halide $7 \mathrm{a}-\mathrm{e}(1.0$ $\mathrm{mmol})$, base $(2.0 \mathrm{mmol}), \mathrm{Pd}-\mathrm{NHC}-\mathrm{MIL}-101(\mathrm{Cr})$ catalyst $(12.0 \mathrm{mg}$, $1.5 \mathrm{~mol} \%), \operatorname{DMF}(5 \mathrm{~mL}), 12 \mathrm{~h}$ at $110^{\circ} \mathrm{C}$. ${ }^{b}$ Isolated yield.

\section{Photophysical properties investigation of compounds 8a-e}

After synthesizing and characterization of D- $\pi-\mathrm{A}$ DSBs, their photophysical properties were investigated and results are depicted in Table 3 and Fig. 3 . All of the distyrylbenzene derivatives showed a broad absorption band between 328-355 nm corresponding to the intramolecular charge transfer (ICT) transfer between donor and acceptor moieties in the molecules. Solvent

Table 3 Photophysical data for DSB derivatives in different solvents

\begin{tabular}{llllll}
\hline Solvent & $\begin{array}{l}\lambda_{\mathrm{ab}} \\
(\mathrm{nm})\end{array}$ & $\begin{array}{l}\lambda_{\mathrm{em}} \\
(\mathrm{nm})\end{array}$ & $\begin{array}{l}\text { Stock shifts } \\
\left(\mathrm{cm}^{-1}\right)\end{array}$ & $\begin{array}{l}\varepsilon \\
\left(\mathrm{L} \mathrm{mol}^{-1} \mathrm{~cm}^{-1}\right)\end{array}$ & $E(\mathrm{eV})$ \\
\hline $\mathbf{8 a}=\mathbf{M}$ & & & & & \\
$\mathrm{DMF}$ & 355 & 540 & 9650 & 96836 & 3.49 \\
$\mathrm{CHCl}_{3}$ & 355 & 552 & 10053 & 73757 & 3.49 \\
$\mathrm{THF}$ & 355 & 529 & 9265 & 94671 & 3.49 \\
Dioxane & 355 & 509 & 8522 & 122904 & 3.49 \\
Toluene & 355 & 507 & 8445 & 88301 & 3.49
\end{tabular}

$\mathbf{8 b}=\mathbf{P}$

$\mathrm{CHCl}_{3}$

355

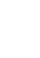

THF

345

535

9372

10293

9325

Dioxane 352

524

$\begin{array}{ll}352 & 506\end{array}$

8646

8611

60756

53302

3.49

Toluene

350

501

67162

62334

3.59

$8 \mathrm{c}=\mathbf{Z}$

DMF

$\mathrm{CHCl}_{3}$

342

\section{2}

THF

$$
545
$$

Dioxane

340

527

Toluene

340

511

\section{2}

11063

10436

9842

9726

64526

3.52

3.52

3.54

$\mathbf{8 d}=\mathbf{I}$

DMF

$\mathrm{CHCl}_{3}$

330

508

52370

65654

69341

56285

65293

THF

Dioxane

330

$$
533
$$

\section{1}

12349

11435

$\begin{array}{ll}504 & 10646\end{array}$

10141

\section{0 \\ 80833 \\ 85460}

3.75

$8 \mathrm{e}=$

DMF

$\mathrm{CHCl}_{3} \quad 345$

541

Dioxane $345 \quad 509$

10087

10803

10081

9339

9261

45461

39392

3.54

Toluene

345
49873

53013

55189 
polarity had minimal effect on the absorption band of all compounds showing their low dipole moment at the ground state. The compounds were found to be fluorescence in all solvents with an emission maximum between $496-550 \mathrm{~nm}$. The large stokes shifts with values between $8445-12349 \mathrm{~cm}^{-1}$ for the samples suggest that the fluorescence could be due to intramolecular charge transfer (ICT). The emission spectra experienced a red shift from 507, 501, 508, 496, and 507 in toluene (least polarity) to 540,
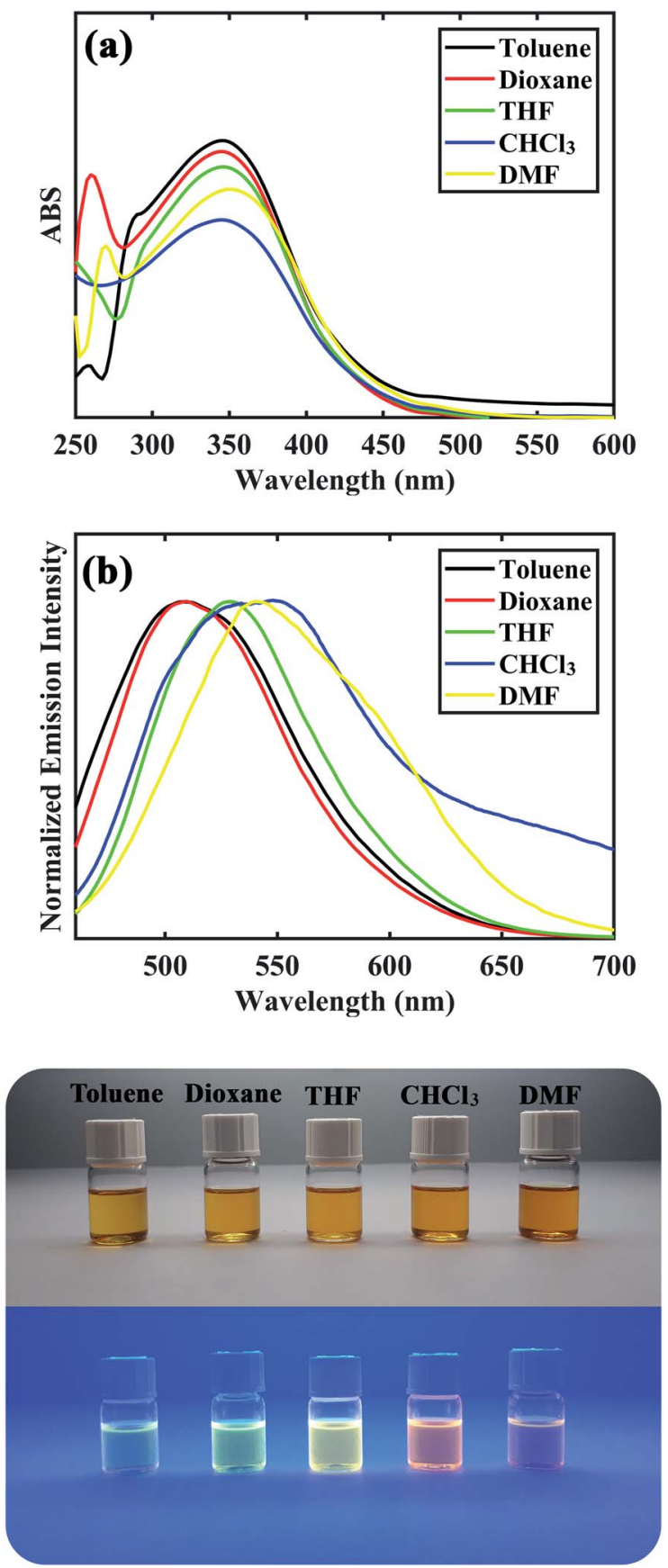

Fig. 3 UV-Vis spectra (a) and emission spectra (b) of $8 c$ at concentration of $10^{-5} \mathrm{M}$ in different solvents. The photographs of the compound in different solutions [from left to right, toluene, dioxane, tetrahydrofuran (THF), chloroform $\left(\mathrm{CHCl}_{3}\right)$, and dimethylformamide (DMF)] were taken under natural daylight simulator (D65) lamps (top image), and irradiation of A-Class UV lamps (bottom image).
$532,532,533$, and 541 in DMF (most polarity) for compounds 8a to 8e, respectively. As shown in Fig. 3, compound 8c showed a bluegreen fluorescence under UV lamp in toluene and its fluorescence changed to green, yellow, and orange hue upon increasing solvent polarity. This trend was also observed for other distyrylbenzene derivatives suggesting a strong positive solvatochromic effect for the compounds (see ESI $\dagger$ ).

The stabilization of the excited state by more polar solvents was the reason for the observed solvatochromism. It should be noted that the more solvent dependency of emission spectra compared to that of absorption spectra for all compounds could be attributed to more ICT characteristic of the samples in their excited state than that of their ground states. ${ }^{69-71}$

The $\mathrm{pH}$ sensitivity of $\mathrm{D}-\pi-\mathrm{A}$ DSBs were also evaluated and results are summarized in Table 4. As detailed in this table, upon decreasing the $\mathrm{pH}$ from 7 to 3 , no meaningful change was observed in emission band of the samples. With further decreasing of the $\mathrm{pH}$ from 3 to 1 , a weak blue shift with values between 15 to $25 \mathrm{~nm}$ was observed for the fluorescent compounds. The observed blue shift could be assigned to diminishing of intramolecular charge transfer (ICT) when the chromophores were protonated by TFA. Surprisingly, a strong red shift with values between 55-83 $\mathrm{nm}$ was detected for the compound $\mathbf{8 c}$ in strong acidic condition.

\section{DFT and TD-DFT calculations}

In order to further clarify the experimental results, the optimized molecular structures of compounds 8a-e DSBs are illustrated in Fig. 4 using density functional theory (DFT) at the B3LYP level. In this work, the B3LYP-D3 and $\omega$ B97XD functional methods which include empirical dispersions were also employed in calculations and their computed maximum absorption wavelengths were found to be more deviated from experimental results.

These DSBs are D- $\pi-\mathrm{A}$ molecules consisting of the same electron withdrawing nitrobenzene moiety as well as different electron donating centers (morpholine, piperidine, piperazine, imidazole, and alanine), which are connected by $\pi$-conjugation in the middle. To illustrate the electronic distribution around molecular surface and also to probe the sites of electrophilic attack (negative potential) and nucleophilic reaction (positive potential) for investigated molecular systems, molecular electrostatic potential (MEP) surfaces were obtained. It is clearly seen in Fig. 4, in the MEP surface for the 8a-e derivatives, oxygen atoms of nitro groups and the center conjugated moieties through the $\pi$-bridge illustrate regions of negative electrostatic potential (electron-rich) while the hydrogen atoms carry the most positive potentials.

Clear elucidation of electron density distribution on the highest occupied molecular orbital (HOMO) and lowest unoccupied molecular orbital (LUMO) of the compounds 8a-e configurations were plotted in Fig. 5. The HOMO of the compounds 8a-e is mainly located to the donor segments whereas the LUMO is concentrated to the terminal nitro substituent which further verified that the charge distribution on such molecules is extremely influenced by $\mathrm{NO}_{2}$. 
Table 4 The $\mathrm{pH}$-sensitivity behavior of synthetic $\mathrm{D}-\pi-\mathrm{A}$ DSBs $8 \mathrm{a}-\mathrm{e}$

\begin{tabular}{|c|c|c|c|c|c|c|c|}
\hline Comp. & $\begin{array}{l}\lambda_{\mathrm{em}} \\
(\mathrm{nm}) \mathrm{pH}=7\end{array}$ & $\begin{array}{l}\lambda_{\mathrm{em}} \\
(\mathrm{nm}) \mathrm{pH}=6\end{array}$ & $\begin{array}{l}\lambda_{\mathrm{em}} \\
(\mathrm{nm}) \mathrm{pH}=5\end{array}$ & $\begin{array}{l}\lambda_{\mathrm{em}} \\
(\mathrm{nm}) \mathrm{pH}=4\end{array}$ & $\begin{array}{l}\lambda_{\mathrm{em}} \\
(\mathrm{nm}) \mathrm{pH}=3\end{array}$ & $\begin{array}{l}\lambda_{\mathrm{em}} \\
(\mathrm{nm}) \mathrm{pH}=2\end{array}$ & $\begin{array}{l}\lambda_{\mathrm{em}} \\
(\mathrm{nm}) \mathrm{pH}=1\end{array}$ \\
\hline \multirow[t]{2}{*}{$8 \mathbf{a}$} & 552 & 552 & 552 & 552 & 552 & 552 & 552 \\
\hline & & & & & 534 & 533 & 530 \\
\hline \multirow[t]{2}{*}{$8 b$} & 535 & 535 & 535 & 535 & 535 & 535 & 535 \\
\hline & & & & & 519 & 518 & 514 \\
\hline \multirow[t]{2}{*}{$8 c$} & 545 & 545 & 545 & 545 & 545 & 545 & 545 \\
\hline & & & & & 530 & 529 & 524 \\
\hline \multirow[t]{2}{*}{$8 d$} & 557 & 557 & 557 & 557 & 557 & 557 & 557 \\
\hline & & & & & 537 & 537 & 533 \\
\hline \multirow[t]{2}{*}{$8 e$} & 550 & 550 & 550 & 550 & 550 & 528 & 526 \\
\hline & & & & & 531 & 605 & 633 \\
\hline
\end{tabular}
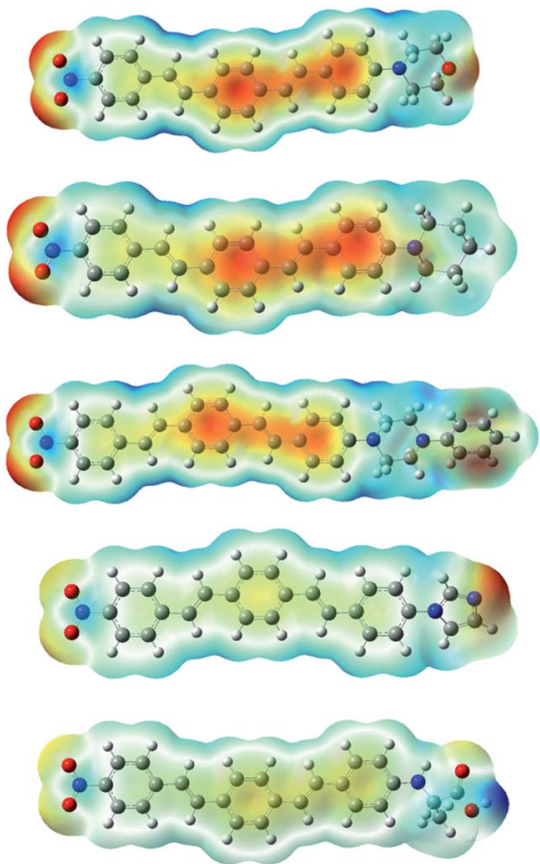

Fig. 4 Optimized structures of $8 a-e$ molecules at the B3LYP/6$31+G(d, p)$ level in the gas phase and electrostatic potential maps. ESP contours are color-coded from red (negative) to blue (positive).

Table 5 signifies the difference between theoretical values of HOMO-LUMO band gap energy for 8a-e DSBs in gas phase and solvent media. The calculated electrochemical band gap energies of the 8a-e derivatives in gas phase are found in the range of 2.41-2.85 eV. The band gap energies were estimated to be in the order of $\mathbf{8 b}<\mathbf{8 e}<\mathbf{8 a}<\mathbf{8 c}<\mathbf{8 d}$ in gas phase. Overall, the band gap of DSBs decreases in selected solvents of varying polarities. As the electric permittivity of the solvents declines along the series DMF $(\varepsilon=37.22)$, THF $(\varepsilon=7.43), \mathrm{CHCl}_{3}(\varepsilon=4.71)$, toluene (2.37), and dioxane $(\varepsilon=2.21)$, the band gap energies of all DSBS increase, respectively. The results clearly reveal that the electron-donating ability of donor moieties in these compounds leads to the changing of band gap energy.

The absorption $\left(\lambda_{\mathrm{ab}}\right)$ and emission $\left(\lambda_{\mathrm{em}}\right)$ wavelengths, the oscillator strength, and main assignments of 8a-e molecules in a variety of solvents were predicted from TD-DFT calculations and listed in Table 6. For instance, the electronic absorption band with the highest wavelength of $\mathbf{8 c}$ compound has been determined at $395.1 \mathrm{~nm}$ in DMF, $394.5 \mathrm{~nm}$ in $\mathrm{CHCl}_{3}, 394.6 \mathrm{~nm}$ in THF, $392.3 \mathrm{~nm}$ in dioxane, and $393.3 \mathrm{~nm}$ in toluene solvent. In line with experimental UV-Vis spectra, the $\lambda_{\mathrm{ab}}$ of $\mathbf{8 d}$ compound is less than others. The electronic absorption of $\mathbf{8 a}-\mathbf{e}$ derivatives essentially originates from HOMO $-1 \rightarrow$ LUMO transition. As obtained for $\mathbf{8 a}-\mathbf{e}$ series, the experimental and calculated maximum absorption values follow a similar trend while some deviations ( 9-11\%) from the experimental values are observed. This deviation could be expected from the bulk

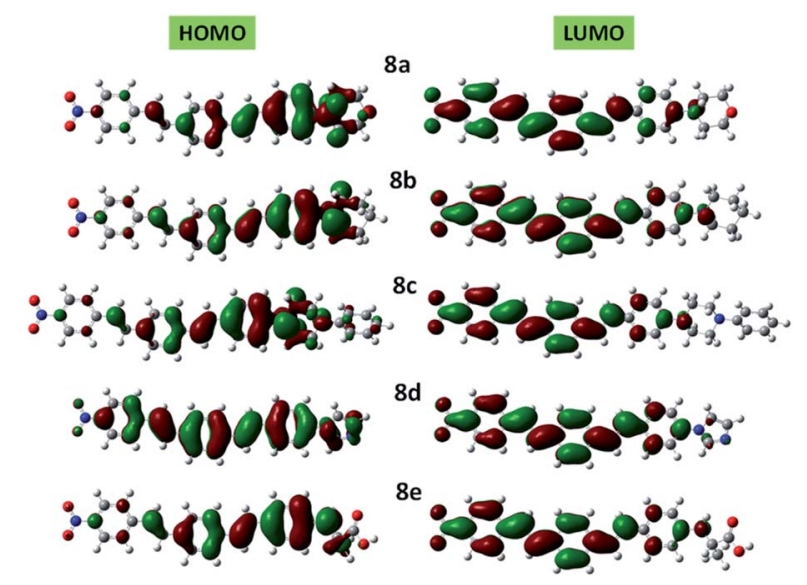

Fig. 5 DFT computed HOMO and LUMO diagrams of $8 \mathrm{a}-\mathrm{e}$ compounds at the B3LYP/6-31+G(d,p) level.

Table 5 The band gap energies (eV) obtained in gas phase and different solvents for $8 \mathrm{a}-\mathrm{e}$ compounds

\begin{tabular}{llllll}
\hline Compound & $\mathbf{8 a}$ & $\mathbf{8 b}$ & $\mathbf{8 c}$ & $\mathbf{8 d}$ & $\mathbf{8 e}$ \\
\hline Gas & 2.48 & 2.41 & 2.46 & 2.85 & 2.42 \\
$\mathrm{DMF}$ & 2.11 & 2.05 & 2.11 & 2.52 & 2.06 \\
$\mathrm{CHCl}_{3}$ & 2.20 & 2.13 & 2.20 & 2.62 & 2.15 \\
THF & 2.16 & 2.10 & 2.17 & 2.58 & 2.12 \\
Dioxane & 2.30 & 2.23 & 2.31 & 2.72 & 2.25 \\
Toluene & 2.30 & 2.22 & 2.30 & 2.70 & 2.23
\end{tabular}


Table 6 Theoretical electronic transition parameters, oscillator strengths and important contributions of the $8 \mathrm{a}-\mathrm{e}$ compounds in the solvent media (TD-B3LYP/6-31+G(d,p))

\begin{tabular}{|c|c|c|c|c|}
\hline Solvent & $\lambda_{\mathrm{ab}}(\mathrm{nm})$ & Osi. stren. & Major contributions & $\lambda_{\text {em }}(\mathrm{nm})$ \\
\hline \multicolumn{5}{|l|}{$8 \mathbf{a}$} \\
\hline DMF & 397.6 & 0.957 & $\mathrm{H}-1 \rightarrow \operatorname{LUMO}(84 \%)$ & 514.1 \\
\hline $\mathrm{CHCl}_{3}$ & 394.6 & 1.042 & $\mathrm{H}-1 \rightarrow \operatorname{LUMO}(78 \%)$ & 486.8 \\
\hline THF & 396.7 & 1.009 & $\mathrm{H}-1 \rightarrow$ LUMO $(81 \%)$ & 502.1 \\
\hline Dioxane & 393.5 & 1.134 & $\mathrm{H}-1 \rightarrow$ LUMO $(68 \%)$ & 463.1 \\
\hline Toluene & 394.5 & 1.118 & $\mathrm{H}-1 \rightarrow \operatorname{LUMO}(70 \%)$ & 465.9 \\
\hline \multicolumn{5}{|l|}{$8 \mathbf{b}$} \\
\hline DMF & 398.1 & 0.985 & $\mathrm{H}-1 \rightarrow$ LUMO $(85 \%)$ & 502.7 \\
\hline $\mathrm{CHCl}_{3}$ & 396.3 & 1.066 & $\mathrm{H}-1 \rightarrow$ LUMO $(79 \%)$ & 495.9 \\
\hline $\mathrm{THF}$ & 396.4 & 1.036 & $\mathrm{H}-1 \rightarrow$ LUMO $(82 \%)$ & 505.6 \\
\hline Dioxane & 392.2 & 1.156 & $\mathrm{H}-1 \rightarrow$ LUMO $(71 \%)$ & 470.8 \\
\hline Toluene & 394.3 & 1.140 & $\mathrm{H}-1 \rightarrow$ LUMO $(72 \%)$ & 474.0 \\
\hline \multicolumn{5}{|l|}{$8 \mathrm{c}$} \\
\hline DMF & 395.1 & 0.505 & $\mathrm{H}-1 \rightarrow$ LUMO $(86 \%)$ & 519.5 \\
\hline $\mathrm{CHCl}_{3}$ & 394.5 & 0.670 & $\mathrm{H}-1 \rightarrow \operatorname{LUMO}(75 \%)$ & 490.5 \\
\hline THF & 394.6 & 0.780 & $\mathrm{H}-1 \rightarrow \operatorname{LUMO}(85 \%)$ & 501.5 \\
\hline Dioxane & 392.3 & 0.519 & $\mathrm{H}-1 \rightarrow$ LUMO $(64 \%)$ & 479.5 \\
\hline Toluene & 393.3 & 0.628 & $\mathrm{H}-1 \rightarrow \operatorname{LUMO}(74 \%)$ & 482.3 \\
\hline \multicolumn{5}{|l|}{ 8d } \\
\hline DMF & 361.6 & 0.891 & $\mathrm{H}-1 \rightarrow$ LUMO $(55 \%)$ & 511.3 \\
\hline $\mathrm{CHCl}_{3}$ & 359.6 & 0.506 & $\mathrm{H}-1 \rightarrow \operatorname{LUMO}(52 \%)$ & 487.2 \\
\hline $\mathrm{THF}$ & 360.2 & 0.521 & $\mathrm{H}-1 \rightarrow \operatorname{LUMO}(44 \%)$ & 508.2 \\
\hline Dioxane & 357.4 & 0.585 & $\mathrm{H}-1 \rightarrow \operatorname{LUMO}(69 \%)$ & 442.6 \\
\hline Toluene & 358.0 & 0.589 & $\mathrm{H}-1 \rightarrow$ LUMO $(70 \%)$ & 473.9 \\
\hline \multicolumn{5}{|l|}{$8 \mathrm{e}$} \\
\hline $\mathrm{DMF}$ & 396.2 & 1.098 & $\mathrm{H}-1 \rightarrow$ LUMO $(77 \%)$ & 503.5 \\
\hline $\mathrm{CHCl}_{3}$ & 394.8 & 1.040 & $\mathrm{H}-1 \rightarrow \operatorname{LUMO}(81 \%)$ & 491.2 \\
\hline THF & 395.1 & 1.012 & $\mathrm{H}-1 \rightarrow$ LUMO $(85 \%)$ & 501.3 \\
\hline Dioxane & 391.9 & 1.030 & $\mathrm{H}-1 \rightarrow$ LUMO $(62 \%)$ & 456.3 \\
\hline Toluene & 393.0 & 1.029 & $\mathrm{H}-1 \rightarrow \operatorname{LUMO}(72 \%)$ & 467.8 \\
\hline
\end{tabular}

solvent effects in experimental conditions while the calculated data are obtained by considering implicit solvent models.

\section{Conclusions}

In conclusion we have developed an efficient palladium catalyst system based on MOFs in the synthesis of a very important class of fluorescence compounds, DSBs, using Heck chemistry. Using this synthetic methodology it is possible to synthesize different DSB derivatives in good to excellent yields. It seems that the MOF structure is effectively facilitate the Heck reaction between bis-alkenes or aryl halides homoselectivity in order to have mono-functionalized products in good yields. Monofunctionalized products in the both forms of vinyl- and halogen-functionalized stilbenes are important in the synthesis of unsymmetrical DSB derivatives which open our hands to have D- $\pi-A$ systems. Using Pd-NHC-MIL-101(Cr) catalyst it is possible to synthesis both symmetrical and unsymmetrical DSBs in high yields. Some new D- $\pi$-A DSBs which are containing different amino groups (D group) and nitro group (A group) were synthesized successfully using this new synthetic methodology in high isolated yields. The photophysical properties of these fluorescence compounds were investigated and DFT calculations were accomplished to investigate the optimized molecular geometry, band gap energy, and the electronic absorption and emission wavelengths.

\section{Conflicts of interest}

There are no conflicts to declare.

\section{Acknowledgements}

Financial support from the research councils of Shiraz University is gratefully acknowledged.

\section{Notes and references}

1 Y. Wang, W. Liu, S. Ye, Q. Zhang, Y. Duan, R. Guo and L. Wang, J. Mater. Chem. C, 2020, 8, 9678-9687.

2 Y. Xu, X. Liang, Y. Liang, X. Guo, M. Hanif, J. Zhou, X. Zhou, C. Wang, J. Yao, R. Zhao, D. Hu, X. Qiao, D. Ma and Y. Ma, ACS Appl. Mater. Interfaces, 2019, 11, 31139-31146.

3 C. H. Lee, S. H. Choi, S. J. Oh, J. H. Lee, J. W. Shim, C. Adachi and S. Y. Lee, $R S C A d v$., 2020, 10, 42897-42902.

4 S. K. Pathak, Y. Xiang, M. Huang, T. Huang, X. Cao, H. Liu, G. Xie and C. Yang, RSC Adv., 2020, 10, 15523-15529.

5 C. Kok, C. Doyranli, B. Canımkurbey, S. P. Mucur and S. Koyuncu, RSC Adv., 2020, 10, 18639-18647.

6 C. Yao, B. Liu, Y. Zhu, L. Hong, J. Miao, J. Hou, F. He and H. Meng, J. Mater. Chem. A, 2019, 7, 10212-10216.

7 X. Du, Y. Yuan, L. Zhou, H. Lin, C. Zheng, J. Luo, Z. Chen, S. Tao and L.-S. Liao, Adv. Funct. Mater., 2020, 30, 1909837.

8 P. Tisovský, A. Gáplovský, K. Gmucová, M. Novota, M. Pavúk and M. Weis, Org. Electron., 2019, 68, 121-128.

9 M. R. Koli, A. Labiod, S. Chakraborty, M. Kumar, P. Lévêque, G. Ulrich, N. Leclerc, D. Jacquemin and S. Mula, ChemPhotoChem, 2020, 4, 729-741.

10 N. De Acha, C. Elosúa, J. M. Corres and F. J. Arregui, Sensors, 2019, 19, 599.

$11 \mathrm{~J}$. Ma, Y. Wang, G. Liu, N. Xu and X. Wang, RSC Adv., 2020, 10, $44712-44718$.

$12 \mathrm{~S}$. Tsumura, K. Ohira, K. Imato and Y. Ooyama, RSC Adv., 2020, 10, 33836-33843.

13 D. Aydin, Talanta, 2020, 210, 120615.

14 L. Long, Y. Han, X. Yuan, S. Cao, W. Liu, Q. Chen, K. Wang and Z. Han, Food Chem., 2020, 331, 127359.

15 H.-Y. Kwon, X. Liu, E. G. Choi, J. Y. Lee, S.-Y. Choi, J.-Y. Kim, L. Wang, S.-J. Park, B. Kim, Y.-A. Lee, J.-J. Kim, N. Y. Kang and Y.-T. Chang, Angew. Chem., Int. Ed., 2019, 58, 8426-8431.

16 W. Chen, T. Matsunaga, D. L. Neill, C. Yang, T. Akaike and M. Xian, Angew. Chem., 2019, 131, 16213-16216.

17 S. Mishra, P. Awasthi, J. Singh, R. K. Gupta, V. Singh, R. Kant, R. Jeet, D. Goswami and A. Goel, J. Org. Chem., 2018, 83, 3669-3678.

18 H. Y. Chung, J. Oh, J.-H. Park, I. Cho, W. S. Yoon, J. E. Kwon, D. Kim and S. Y. Park, J. Phys. Chem. C, 2020, 124, 1850218512. 
19 I.-H. Park, L. Chu, K. Leng, Y. F. Choy, W. Liu, I. Abdelwahab, Z. Zhu, Z. Ma, W. Chen, Q.-H. Xu, G. Eda and K. P. Loh, Adv. Funct. Mater., 2019, 29, 1904810.

20 A. Granados and A. Vallribera, Dyes Pigm., 2019, 170, 107597.

21 A. Gopinath, K. Ramamurthy, M. Subaraja, C. Selvaraju and A. S. Nasar, New J. Chem., 2018, 42, 10243-10253.

22 E. Zamani, H. Yahyaei, A. Khosravi, M. Mohseni and H. Shaki, J. Macromol. Sci., Part B: Phys., 2019, 58, 772-781.

23 M. Pilehkouhi, H. Shaki, A. Khosravi, M. Khorasani and E. Zamani, J. Macromol. Sci., Part B: Phys., 2018, 57, 151-167.

24 E. Zamani, H. Shaki, M. Rafizadeh, A. Khosravi and M. Pilehkouhi, Fibers Polym., 2017, 18, 1431-1437.

25 Z. Li, B. Huang, Y. Wang, W. Yuan, Y. Wu, R. Yu, G. Xing, T. Zou and Y. Tao, RSC Adv., 2020, 11, 160-163.

26 W. M. Pazin, A. K. A. Almeida, V. Manzoni, J. M. M. Dias, A. C. F. de Abreu, M. Navarro, A. S. Ito, A. S. Ribeiro and I. N. de Oliveira, RSC Adv., 2020, 10, 28484-28491.

27 G. Ji, N. Wang, X. Yin and P. Chen, Org. Lett., 2020, 22, 57585762.

28 F. Gao, L. Yang, L. Yang, H. Li and S. Zhang, J. Fluoresc., 2010, 20, 353-364.

29 S. Mukherjee, P. Pal, D. Maity and S. Baitalik, J. Photochem. Photobiol., A, 2019, 378, 94-104.

30 B. Łukasik, J. Milczarek, R. Pawlowska, R. Żurawiński and A. Chworos, New J. Chem., 2017, 41, 6977-6980.

31 J. Shi, M. A. Izquierdo, S. Oh, S. Y. Park, B. Milián-Medina, D. Roca-Sanjuán and J. Gierschner, Org. Chem. Front., 2019, 6, 1948-1954.

32 D. C. Harrowven, I. L. Guy, M. Howell and G. Packham, Synlett, 2006, 2006, 2977-2980.

33 Z. A. Khan, A. Iqbal and S. A. Shahzad, Mol. Diversity, 2017, 21, 483-509.

34 H. Meier, S. Kim and A. Oehlhof, Synthesis, 2009, 2009, 848852.

35 A. Szukalski, K. Parafiniuk, K. Haupa, W. Goldeman, B. Sahraoui, F. Kajzar and J. Mysliwiec, Dyes Pigm., 2017, 142, 507-515.

36 V. Tyagi and R. Fasan, Angew. Chem., 2016, 128, 2558-2562.

37 A. Karbach, T. Stemler, C. Kopp and W. E. Trommer, Synthesis, 2014, 46, 3103-3109.

38 M. Singh and N. P. Argade, Synthesis, 2012, 44, 2895-2902.

39 H. H. Rau and N. S. Werner, Bioorg. Med. Chem. Lett., 2018, 28, 2693-2696.

40 N. Rameau, B. Russo, S. Mangematin, C. Pinel and L. Djakovitch, Appl. Catal., A, 2018, 560, 132-143.

41 C. I. Traficante, C. Fagundez, G. L. Serra, E. G. Mata and C. M. L. Delpiccolo, ACS Comb. Sci., 2016, 18, 225-229.

42 T. R. Girase and A. R. Kapdi, Chem.-Asian J., 2019, 14, 26112619.

43 F. C. Demidoff, F. P. de Souza and C. D. Netto, Synthesis, 2017, 49, 5217-5223.

44 A. Skhiri, R. B. Salem, J.-F. Soulé and H. Doucet, Synthesis, 2016, 48, 3097-3106.

45 A. Mahmoodi, F. Panahi, F. Eshghi and E. Kimiaei, J. Lumin., 2018, 199, 165-173.

46 F. S. Miri, S. Gorji Kandi and F. Panahi, J. Fluoresc., 2020, 30, 917-926.
47 H. Karimi-Alavijeh, F. Panahi and A. Gharavi, J. Appl. Phys., 2014, 115, 093706.

48 M. T. Sharbati, F. Panahi, A.-R. Nekoei, F. Emami and K. Niknam, J. Photonics Energy, 2014, 4, 043599.

49 M. T. Sharbati, F. Panahi and A. Gharavi, IEEE Photonics Technol. Lett., 2010, 22, 1695-1697.

50 F. Panahi, A. Mahmoodi, S. Ghodrati and F. Eshghi, RSC Adv., 2020, 11, 168-176.

51 E. Niknam, F. Panahi and A. Khalafi-Nezhad, Appl. Organomet. Chem., 2020, 34, e5470.

52 K. R. Balinge and P. R. Bhagat, C. R. Chim., 2017, 20, 773.

53 Y.-Q. Tang, J.-M. Lu and L.-X. Shao, J. Organomet. Chem., 2011, 696, 3741.

54 A. V. Astakhov, O. V. Khazipov, A. Y. Chernenko, D. V. Pasyukov, A. S. Kashin, E. G. Gordeev, V. N. Khrustalev, V. M. Chernyshev and V. P. Ananikov, Organometallics, 2017, 36, 1981.

55 M. Sreenivasulu, K. S. Kumar, P. R. Kumar, K. B. Chandrasekhar and M. Pal, Org. Biomol. Chem., 2012, 10, 1670.

56 A. L. Gottumukkal, J. G. de Vries and A. J. Minnaard, Chem.Eur. J., 2011, 17, 3091.

57 M. A. Taige, A. Zeller, S. Ahrens, S. Goutal, E. Herdtweck and T. Strassner, J. Organomet. Chem., 2007, 692, 1519.

58 The ICP analysis of Pd-NHC-MIL-101(Cr) catalyst shows that it contains $1.3 \mathrm{mmol} \mathrm{g}^{-1}$ of $\mathrm{Pd}$.

59 S. Bhavania, M. A. Ashfaq, D. Rambabu, M. V. B. Rao and M. Pal, Arabian J. Chem., 2019, 12, 3836.

60 A. Perosa, P. Tundo, M. Selva, S. Zinovyeva and A. Testa, Org. Biomol. Chem., 2004, 2, 2249.

61 K. Khler, R. G. Heidenreich, J. G. E. Krauter and J. Pietsch, Chem.-Eur. J., 2002, 8, 622.

62 X.-Y. Zhou, X. Chen and L.-G. Wang, Synthesis, 2017, 49, 5364.

63 M. A. Zolfigol, K. Amani, A. Ghorbani-Choghamarani, M. Hajjami, R. Ayazi-Nasrabadi and S. Jafari, Catal. Commun., 2008, 9, 1739.

64 J. Kumpf, J. Freudenberga and U. H. F. Bunz, Analyst, 2015, 140, 3136.

65 Z. A. Kasun, H. Sato, J. Nie, Y. Mori, J. A. Bender, S. T. Roberts and M. J. Krische, Chem. Sci., 2018, 9, 7866.

66 J. Zhang, A. Konsmo, A. Sandberg, X. Wu, S. Nyström, U. Obermüller, B. M. Wegenast-Braun, P. Konradsson, M. Lindgren and P. Hammarström, J. Med. Chem., 2019, 62, 2038-2048.

67 I.-H. Park, K. Sasaki, H. S. Quah, E. Lee, M. Ohba, S. S. Lee and J. J. Vittal, Cryst. Growth Des., 2019, 19, 1996-2000.

68 M. Suen, L. Hang, W. Lee, A. S. C. Chan and F. Y. Kwong, Tetrahedron Lett., 2008, 49, 6192-6194.

69 A. Paul, A. Biswas, S. Sinha, S. S. Shah, M. Bera, M. Mandal and N. D. P. Singh, Org. Lett., 2019, 21, 2968-2972.

70 A. Gopinath, K. Ramamurthy, M. Subaraja, C. Selvaraju and A. S. Nasar, New J. Chem., 2018, 42, 10243-10253.

71 S. Mishra, P. Awasthi, J. Singh, R. K. Gupta, V. Singh, R. Kant, R. Jeet, D. Goswami and A. Goel, J. Org. Chem., 2018, 83, 3669-3678. 